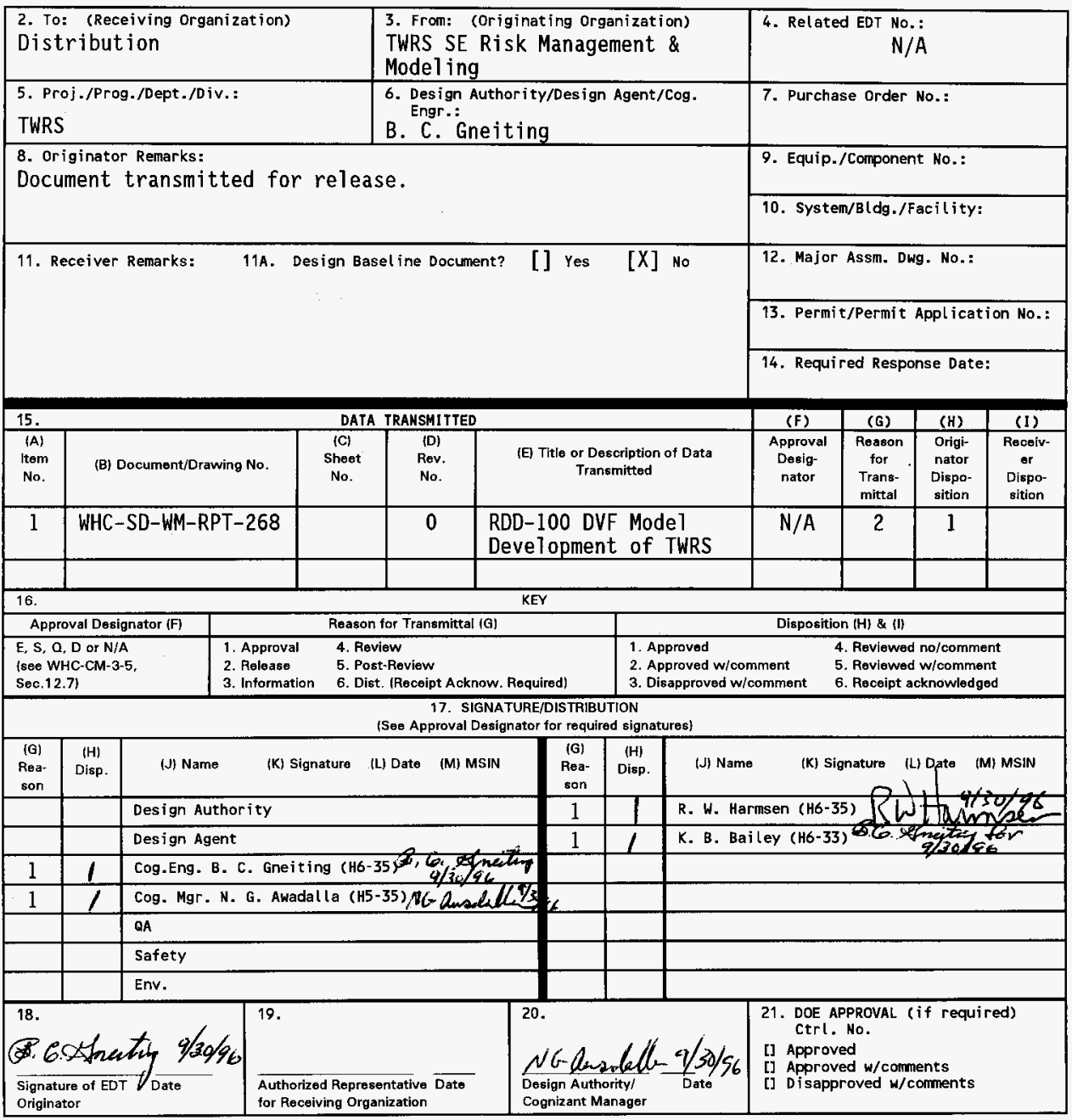

BD-7400-172-2(05/96) GEF097 


\title{
RDD-100 DVF Model Development for TWRS
}

\author{
K. B. Bailey, HHC \\ R. W. Harmsen, WHC \\ K. Keeton, Ascent Logic Corp. \\ B. C. Gneiting, WHC
}

WHC, Richland, WA 99352

U.S. Department of Energy Contract DE-AC06-87RL10930

\author{
EDT/ECN: $618215 \quad$ UC: 2030 \\ Org Code: 74450 Charge Code: D1MIM \\ B\&R Code: EW3120075 Total Pages: 22
}

Key Words: technical baseline, simulation, RDD-100, systems engineering, modeling, verification.

Abstract: The purpose of this document is to describe the work performed to develop an executable model of the TWRS technical baseline using the RDD-100 Dynamic Verification Facility. The benefit of developing a DVF model that simulates the conceptual TWRS baseline system is that is provides a verification of the system performance and the traceability needed between the system requirements and the proposed architectures that will satisfy the requirements and perform the identified functions. The initial modeling results showed some potential interface and scheduling conflicts between some of the TWRS components.

TRADEMARK DISCLAIMER. Reference herein to any specific comercial product, process, or service by trade name, tradenark, manufacturer, or otherwise, does not necessarily constitute or imply its endorsement, recommendation, or favoring by the United States Government or any agency thereof or $i$ ts contractors or subcontractors.

Printed in the United States of America. To obtain copies of this document, contact: WHC/BCS Document Control Services, P.O. Box 1970, Mailstop H6-08, Richland WA 99352, Phone (509) 372-2420; Fax (509) 376-4989.
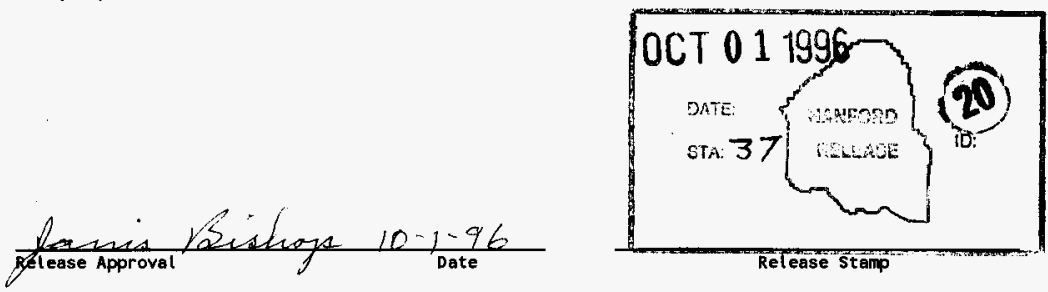
WHC-SD-WM-RPT-268, Rev. 0

TABLE OF CONTENTS

1.0 INTRODUCTION . . . . . . . . . . . . . . . . . . . . . 1

2.0 ASSUMPTIONS FOR BEHAVIORAL MODEL ............... 2

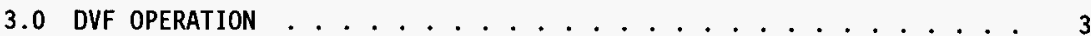

3.1 Double-Sheli Tank Resource Monitor . . . . . . 3

3.2 Animation, Time Lines, and Resource/Product Graphs . . . . . 3

4.0 TWRS MODEL DETAILS ....................... 4

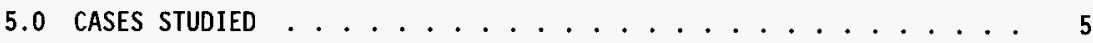

6.0 RESULTS AND DISCUSSIONS ........................ 5

7.0 CONCLUSIONS .............................. 5

8.0 FUTURE WORK ......................... 6

9.0 REFERENCES ...................... . . 6

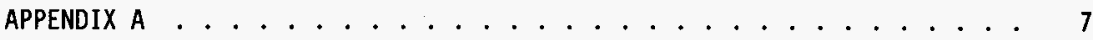

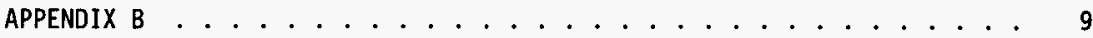

\section{LIST OF FIGURES}

FIGURE 1. TANK WASTE STORAGE SYSTEM LIFE CYCLE BEHAVIOR DIAGRAM . . . 11

FIGURE 2. WASTE RETRIEVAL SYSTEM TIME LINE . . . ....... 12

FIGURE 3. IMMOBILIZED WASTES INTERIM STORAGE TIME LINE . . . . . . . . 13

FIGURE 4 , TOTAL STORED TANK WASTE VERSUS TIME $\ldots \ldots \ldots$

FIGURE 5. WASTE RETRIEVAL STRATEGY LIFE CYCLE BEHAVIOR DIAGRAM $: \cdots \cdot 15$

FIGURE 6. SINGLE SHELL TANK RETRIEVAL (CUMULATIVE DILUTE) VERSUS TIME : 16

FIGURE 7. DOUBLE SHELL TANK RETRIEVAL (CUMULATIVE DILUTE) VERSUS TIME • 17

FIGURE 8. PRETREATED HLW/TRU LAG STORAGE USAGE . . . . . . . . . . 18

FIGURE 9. PRETREATED LLW LAG STORAGE USAGE . . . . . . . . . . . . . . 19

FIGURE 10 . INTERIM STORED HLW/TRU GLASS VERSUS TIME . . . . . . . 20 


\subsection{INTRODUCTION/SUMMARY}

This report describes work performed in the first half of fiscal year (FY) 1996 for the SE Risk Management and Modeling's work task titled "Model of the TWRS Baseline System within RDD-100 DVF." The purpose of this task was to construct an executable model of the Tank Waste Remediation System (TWRS) base]ine system using the Dynamic Verification Facility ${ }^{m 1}$ (DVF) of the RDD-100 systems engineering software support tool. The benefit of developing a DVF model that simulates the conceptual TWRS baseline system is that it provides a verification of the system performance and the traceability needed between the system requirements and the proposed architectures that will satisfy the requirements and perform the identified functions.

Early in the model development stage a significant problem was encountered with the irregular condition of the behavior data stored in the RDD-100 database; it was not in a format required to run the DVF. For instance, to run the DVF, functions (activities) need to have one input and one output. Therefore functions with multiple inputs and outputs have to be aggregated. Also, decompositions of high-level inputs and outputs for highlevel functions have to be made consistent. Finally, some inputs are not generated and some outputs and not consumed. This translates into an incomplete interface definition between functions. The process for developing an executable DVF model is discussed further in Appendix A.

Rather than make extensive changes to the TWRS technical baseline structure, an alternate approach was taken in the interim. It was decided to limit the model to the fourth functional level and adopt a new approach based on the "operational scenarios" modeling work being performed by the TWRS Technical Integration (TTI) staff. A cooperative effort with TTI staff resulted in development of a life-cycle model detailed down to the fourth functional level in the TWRS area. The new approach essentially uses an a] ternate decomposition of the third level functions into discrete fourth level functions with discrete inputs and outputs. These decomposed items summarize the fourth level behavior without directly affecting the technical baseline data. 
WHC-SD-WM-RPT-268, Rev. 0

The DVF model developed by the TTI staff was used as a starting point with process timing, such as tank retrieval sequences, aggregated from other baseline models developed in ARENA $\mathrm{m}^{2}$ and ithink $\mathrm{m}^{\mathrm{m}} \mathrm{s}$ simulation languages. The system performance results from the DVF model were optimistic relative to the ARENA and ithink models because sludge wash delays were not modeled. The modeling results showed several interface and scheduling conflicts between components. Two such cases involved WESF and TWRS support facilities:

1. A simple decision to delay acceptance of the cesium/strontium capsules from the Waste Encapsulation and Storage Facility (WESF) indicated a significant impact on the WESF life-cycle cost.

2. Likewise, slightly increasing the throughput of the high-level waste (HLW) and low-level waste (LLW) vitrification plants resulted in completion by 2020 rather than 2028 . This in turn significantly impacts the specifications for support facilities including Solid Waste Disposal and Liquid Effluent Treatment.

\subsection{ASSUMPTIONS FOR BEHAVIORAL MODEL}

The existing TWRS functions defined in the TWRS baseline are used in the DVF behavioral model, although some control functions were added and some TimeItem decompositions were changed to correct inconsistencies.

Using the DVF behavioral model, requirements of the Hanford Federal Facility and Consent Order (Tri-Party Agreement) are met:

- Single-shell tank (SST) interim stabilization is completed before 2000

- Saltcake retrieval from the 16 TX Farm tanks is completed before 2009

- The remaining 133 SSTs are retrieved by 2019

- Only 18 percent of the SST waste is retrieved in the first eight years

with the remaining 82 percent retrieved in six years

SST waste is taken as homogeneous with a retrieval water addition factor of 2.378 .

Double-shell tank (DST) waste retrieval is at a constant rate during the first six years of SST retrieval. DST waste is taken as homogeneous with a retrieval water addition factor of 0.60545 . LLW pretreatment begins by 2005 . Vitrification of all tank waste is completed by 2028.

ithink is a trademark of High Performance Systems, Inc. 
Only the existing 28 one-million-galion (Mgal) DSTs are available for lag storage. No new underground tanks are added. SSTs may be used to store present contents and are closed after the tank contents have been retrieved. Evaporators have a storage capacity of 750 kilogallons and throughput capacity sufficient to remove surplus water during peak tank retrieval in parallel with sludge wash processing. The existing DSTs provide storage of existing waste and waste retrieved from SSTs. The DSTs are used for in-tank sludge wash processing. Also, DSTs provide all feed lag storage for pretreatment facilities, demonstration glass plants, and LLW and HLW full-scale glass plants.

\subsection{DVF OPERATION}

The model is made part of the technical baseline through the use of the DVF of RDD-100 in which the functions, requirements, interfaces, issues, and decisions for TWRS reside. The model is built using behavioral diagrams that are graphically constructed. Concurrent processes are spaced horizontally on vertical branches containing the sequential functions that define each process. A "time token" falls from the top of the diagram through the functions to the bottom of the diagram when the simulation is complete. Functions respond to controls to transform input to outputs using resources and consuming a programmed amount of time. TimeItems are used to define inputs, outputs, controls, and resources and are connected between functions. On branches, iteration loops provide a re-execution of functions and processes while termination criteria provides exit logic. Controller (programmatic) functions enable process functions on scheduled dates representing the availability of a process facility or component.

\subsection{Double-She11 Tank Resource Monitor}

The use of DSTs is controlled by the resource monitor. Functions that require the DST resource to execute consume the amount of resource needed at the beginning of execution and release the resource on completion. The resource monitor keeps track of the remaining DST resource and inhibits execution of functions when the resource is unavailable.

\subsection{Animation, Time Lines, and Resource/Product Graphs}

A control panel is used to control execution of the model and to define time lines and graphs to be created during run time. When the model is running and functions have been triggered and are executing, those functions are shaded. TimeItems are shaded when passing between functions. Function and process time lines, as well as resource and product graphs, are updated on the screen as the simulation proceeds. 
WHC-SD-WM-RPT-268, Rev. 0

\subsection{TWRS MODEL DETAILS}

- Tank waste is retrieved in three-month increments and moved to $1 \mathrm{ag}$ storage or sludge wash at the beginning of each interval.

- The SST retrieval is based on "Initial SST Retrieval System Tank Selection," Reference 3.

- Lag storage tanks are modeled as a shared resource using the resource monitor utility.

- Processes remove waste from lag storage on a monthly basis, therefore consuming the monthly plant capacity at the beginning of each month.

- Plants pass their products to lag storage at the beginning of each monthly interval. HLW pretreatment, or enhanced sludge wash, is the exception.

- Enhanced sludge wash differs for DSTs and SSTs. DST processing requires five, one-month cycles with $0.73 \mathrm{Mgal}$ feed per cycle and $3.45 \mathrm{Mga}$ wash water added per Mgal feed. The DST process produces $3.082 \mathrm{Mga} 1$ supernatant per cycle and $0.722 \mathrm{Mgal}$ sludge every fifth cycle. SST processing requires three, one-month cycles with $0.833 \mathrm{Mgal}$ feed per cycle and $2.79 \mathrm{Mgal}$ wash water added per Mgal feed. The SST process produces $3.22 \mathrm{Mgal}$ supernatant per cycle and $0.647 \mathrm{Mgal}$ sludge every three cycles.

- Three DST processes operate in parallel with starts staggered by two months. Two SST processes operate in parallel with starts staggered by two months.

Evaporators have sufficient capacity to handle peak flow rates from retrieval and sludge wash operations with negligible delay. LLW pretreatment has an input capacity of $1.40 \mathrm{Mgal}$ per month and cesium removal is not explicitly modeled.

- Initial waste vitrification (Privatization Phase 1) is provided by two LLW vitrification demonstration plants having input capacities of 0.022 Mgal per month. Each plant produces 67.3 cubic meters of 30 percent. waste oxide glass per month.

- A single HLW vitrification demonstration plant has an input capacity of $0.025 \mathrm{Mgal}$ per month and produces 11.35 cubic meters of 45 percent waste oxide glass per month.

- Each demonstration glass plant processes $1.0 \mathrm{Mgal}$ of tank waste.

- Nine years after starting the LLW vitrification demonstration plants, the full-scale LLW vitrification plant begins operation (Privatization Phase 2). This plant has an input capacity of $0.25 \mathrm{Mgal}$ per month and produces 750 cubic meters of 30 percent waste oxide glass per month. The full-scale HLW vitrification plant comes on line two-and-one-half years later. This plant has an input capacity of $0.20 \mathrm{Mgal}$ per month and produces 87 cubic meters of 45 percent waste oxide glass per month. 
These plants evaporate, condense, and recycle significant quantities of water, although these processes are not modeled.

- HLW glass is shipped to a geologic repository at a constant rate, reducing onsite inventory to zero by the year 2040 .

\subsection{CASES STUDIED}

The initial case studied had a HLW vitrification demonstration plant and full-scale HLW and LLW vitrification plants. The HLW processing rate was $0.33 \mathrm{Mgal}$ per month and the LLW processing rate was 0.301 Mgal per month. The sludge wash delays were negligible. The planned second case was to add expected sludge wash delays and to reduce the vitrification plant capacities to the Privatization Phase 2 values.

\subsection{RESULTS AND DISCUSSIONS}

For the initial case, pretreated HLW lag storage requirements peaked at 11 Mgal, twice as large as indicated by the TWRS ithink model, which has delays for sludge wash. The missing sludge wash delays also caused pretreated LLW lag storage demand to peak at 30 million gallons, which is physically unrealizable. Also, vitrification was completed in 2019, creating interface problems with support projects expecting feed through 2028.

The model demonstrated that this SST retrieval sequence results in completion of the $16 \mathrm{TX}$ Farm tanks in October 2011. This is two and threequarter years past the Tri-Party Agreement milestone.

The planned second case has not yet been run.

\subsection{CONCLUSIONS}

The DVF successfully demonstrated TWRS behavior in the context of other Site projects and programs. Although several interface and scheduling conflicts were uncovered, these were used to find oversights in the model and to suggest parametric studies to optimize system operating parameters, such as plant capacities. The DVF does not yet evaluate TWRS detailed behavior. 


\subsection{FUTURE WORK}

The present DVF model is high level, with much aggregation of material streams. A clearer understanding of system behavior will be achieved as the model is developed in greater detail. Several useful enhancements are 1isted below:

- Revisit baseline structure and systems engineering process:

- Resolve TimeItem inconsistencies.

- Correct Timefunction hierarchies.

- Provide more frequent merges of TWRS models into the Site baseline.

- Control and document the baseline change process, rather than just documenting the process.

- Define timing details (Timefunction start, duration, sequencing, abnormal termination, and interfaces).

- Add functionality to the model:

- Provide separate processing of 16 TX Farm saltcake SSTs, rather than aggregation with 133 remaining sludge tanks.

- Increase detail of evaporators adding capacity limits.

- Add cesium separations to the LLW pretreatment facility.

- Extended resource monitor use to better track tank usage, water recycle, and other critical resources.

- Model water recovery and recycle from glass plants.

- Connect the TWRS water resource pool to waste water from other projects and programs.

- Plan and execute a large number of parametric runs to demonstrate compatibility and efficient TWRS operations in context with other Hanford Site cleanup activities.

\subsection{REFERENCES}

(1) WHC-SC-WM-TI-687, Draft Revision 0, "Baseline Simulation Model for Hanford Tank Waste Remediation System," Richard Wittman, dated March 1995.

(2) WHC-SC-WM-DR-013, Revision 0, "Waste Pretreatment and Interfacing Systems Dynamic Simulation Model," David Garbrick, dated June 19, 1995.

(3) WHC-SD-WM-ES-376, Draft Revision 0, "Initial SST Retrieval System Tank Selection," Charles Grenard, dated February 1996. 
WHC-SD-WM-RPT-268, Rev. 0

\section{APPENDIX A}

The major problem with the current TWRS baseline model in terms of execution is that multiple inputs and outputs (TimeItems in RDD terms) are connected to multiple functions (TimeFunctions in RDD terms). The DVF uses these connections in a special way. If a function has an input, it will not execute until it is triggered by that input. If the input is not received, the simulation ends in an error. If an output does not trigger another function, the DVF stops with an error.

In order to make the model execute, each of the non-decomposed TimeFunctions is decomposed one level further into a dummy function without connecting the current inputs and outputs to the lower level function. This has the effect of stubbing the function. Since the dummy function is not connected to any inputs or outputs, it does not need to wait for a trigger in order to execute, although no products (outputs) are generated. When the higher level function is enabled, the dummy function is immediately executed. The high level function simply becomes a device for aggregating functionality, but represents no functionality itself. Additionally, the dummy function provides no functionality. By manipulating the TimeItems and TimeFunctions to be consistent with the DVF, the model now "executes", although the model does not yet simulate any functionality. However, since all inputs, outputs, and functions are contained in the model the model can be systematicaliy improved over time to provide a fully functional TWRS simulation.

Functional decompositions below the fourth level do not truly represent the system. The difficulty lies with inappropriate use of TimeItems. There are three problems with the current usage of TimeItems:

1) TimeItems that are not input to or output from TimeFunctions in the same hierarchy as their parents;

2) leveling inconsistencies where children and parent TimeItems are not input and output at levels consistent with their place in the TimeItem hierarchy; and

3) multiple TimeItems (often at different hierarchical levels) are input to or output from multiple TimeFunctions.

These problems prevent execution of the current TWRS model. In order for the model to execute, only one TimeItem may be input to a Timefunction that is not decomposed into lower levels. In short, this means that one of two things must occur before this model will demonstrate TWRS behavior. Either the TimeItems must be aggregated into a higher level TimeItem where multiple TimeItems are input to a Timefunction, or the TimeFunctions must be decomposed, creating a one-to-one relationship at the lowest hierarchical level between input TimeItems and Timefunctions. Both of these approaches will require substantial knowledge of TWRS and an understanding of the functionality of the DVF. 
The model has proven beneficial by pointing out that the function inputs and outputs are not fully defined. Some inputs are not generated and some outputs are not consumed. This translates into an incomplete interface definition between functions. Significant benefit in the area of interface definition and verification of functional interdependencies are realized when the model is made executable. Timing is verified and functionality is refined. The database provides a record of conflict resolution. Adding timing and sequencing information provides the capability to verify that requirements can be met. Perhaps most importantly, traceability will be maintained throughout the process of requirement definition and analysis, functional analysis, allocation to architectures, system and process design, and system simulation/verification. In addition, by using the extended capabilities of v4.0.3 (standardized consistency checks and reports) after the conversion is complete, impact analysis will be more readily performed when changes are requested.

The fixes to the TWRS model need to be integrated with the technical baseline. The changes could be extensive. The TimeItem hierarchy will need to be evaluated from the top down and possibly completely revamped. These modifications will be required to make the model simulate system behavior. of course, periodic updates are preferable in order to avoid massive numbers of errors when importing changes. An alternative to modifying the baseline is to produce some scenarios representing critical threads of the behavior. These scenarios would have little or no effect on the technical baseline. This also implies that there will be no direct tie back to the baseline. In order to have a meaningful dynamic model, it must affect the baseline.

In summary, to complete this task, at least one engineer with a knowledge of TWRS and approximately one to two months of calendar time will be required. The $\mathrm{plan}$ is to continue to develop the model, with the help of TWRS engineers, to include the timing and sequencing of the system. The model will become increasingly useful as functions and their interdependencies are defined. This is the recommended approach. If time, budget, or priority does not permit this approach, an alternate approach is to generate several scenarios representing the critical behavior of the system. These scenarios will not reflect the overall system behavior, strictly speaking, but only look at the part of behavior that is of special interest. 


\section{APPENDIX B}

Time Lines and Resource/Product Graphs Produced by the Dynamic Verification Facility

The time lines for graphically depicting function execution are defined on the key to the right. Resource wait means the resource monitor has detected the function is ready to execute but lacks a required resource. Triggered execution indicates the function is triggered and executing. Item link wait means a needed input is waiting in an item link priority queue. Time out means a function timed out before it could execute.

Resource and product graphs show the resource or product on the vertical axis and year on the horizontal axis. Tank retrieval graphs show quarterly totals as pulses at the beginning of each quarter. This is done to assure that no artificial

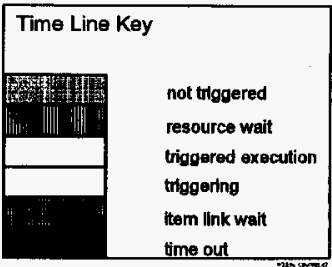
lags are introduced by retrieval.

Behavior diagrams are provided for reference. Function names are provided in rectangles; TimeItem names are provided in ovals; and process names are provided at the top of each vertical branch line. The " $\&$ " symbol represents concurrent execution of parallel processes.

The following behavior diagrams, time 1 ines, and resource/product graphs present the system behavior for Case 1. Figure 1 provides the behavior diagram for the Tank Waste Storage System. This system responds to "Request for DST Waste" and "Request for SST Waste" from the Tank Waste Retrieval System. Figures 2 and 3 show the time lines for the Tank Waste Retrieval and Immobilized Wastes Interim Storage Systems, respectively. Tank Waste Processing System time lines are not shown because these processes are not well developed in Case 1; however, splits between HLW, LLW, and evaporated water products are in place. Figure 4 show stored, untreated tank waste versus time, while Figure 5 shows the behavior diagram for the Waste Retrieval System. "DST Waste for Retrieval" and "SST Waste for Retrieval" are retrieved from the Tank Waste Storage System on pre-arranged schedules. Figure 6 shows the retrieval of SST waste. Generally, TX Tank Farm waste (saltcake) is retrieved first, followed by the remaining 133 SSTs. The shape of the DST retrieval curve is not yet specified but a linear assumption was used (Figure 7). 
Lag storage versus time for pretreated $H L W$ and transuranic waste is shown in Figure 8 . The start up of HLW Immobilization is seen clearly as the initial declining slope. The final slope represents a period in which retrieval is complete. Figure 9 shows lag storage for pretreated LLW. The initial hump is waste used to feed the LLW vitrification demonstration plant. This is worked off and then accumulation for the full-scale vitrification plant begins. Finally, interim stored, immobilized HLW (glass) versus time is shown in Figure 10. The initial slope represents throughput from the HLW vitrification demonstration plant. The negative slope represents shipment to the geologic repository.

Case 2 results are not available at the time of publishing this report. 
WHC-SD-WM-RPT-268, Rev . 0

FIGURE 1. TANK WASTE STORAGE SYSTEM LIFE CYCLE BEHAVIOR DIAGRAM

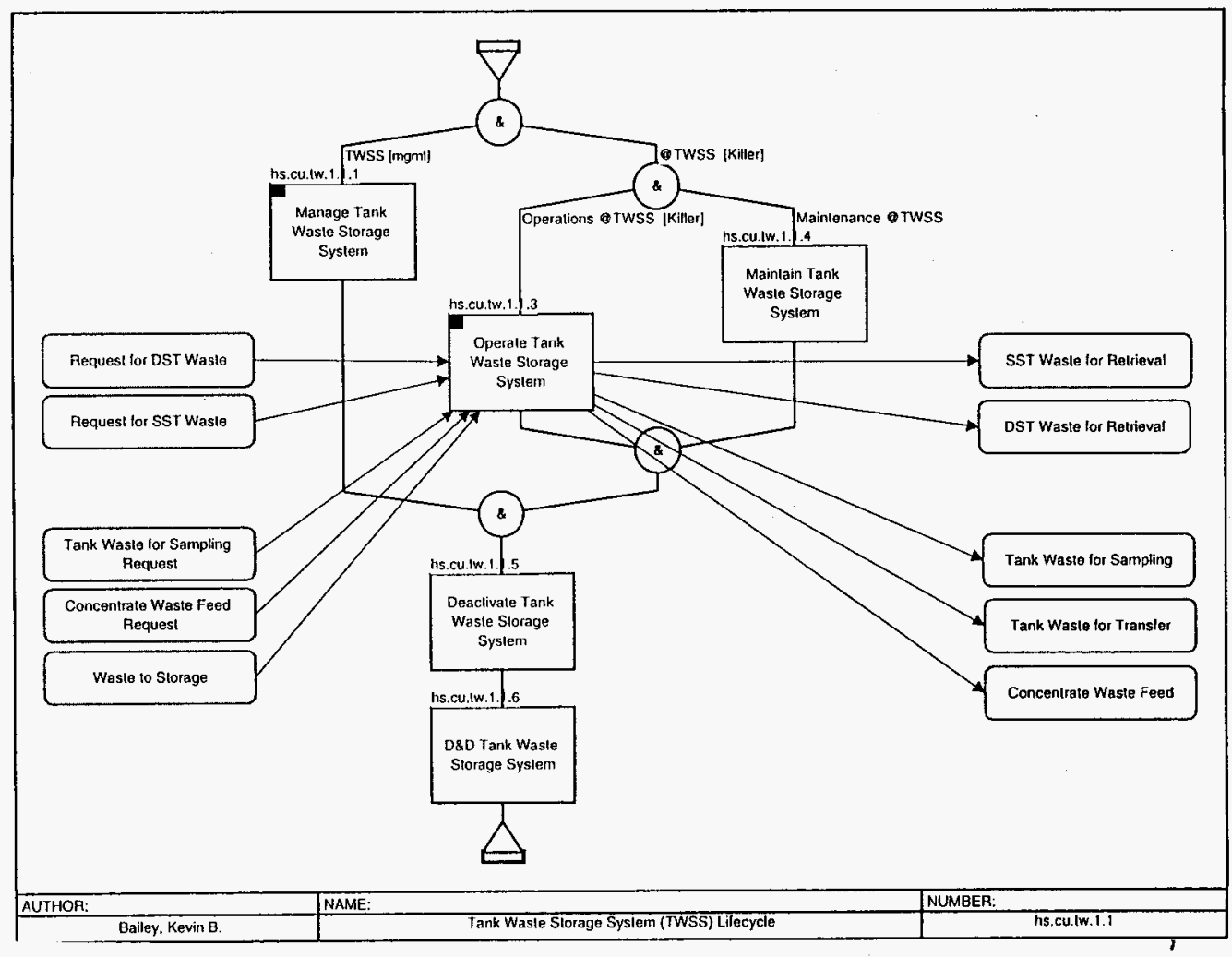


WHC-SD-WM-RPT-268, Rev. 0

FIGURE 2. WASTE RETRIEVAL SYSTEM TIME LINE

\begin{tabular}{|c|c|c|c|c|c|c|c|c|}
\hline , & ]$^{2005}$ & $\begin{array}{c}2007 \\
1\end{array}$ & $\begin{array}{c}2009 \\
1\end{array}$ & $\frac{2011}{1}$ & $\underbrace{2013}_{12013}$ & $\begin{array}{c}2015 \\
1\end{array}$ & $\stackrel{2017}{1}$ & $\begin{array}{r}201: \\
1\end{array}$ \\
\hline \multicolumn{9}{|l|}{ Wall for LLW rretreatment to Come on Line } \\
\hline \multicolumn{9}{|l|}{ Wan for HLW Pretre atment to come on IIne } \\
\hline \multicolumn{9}{|l|}{ Inituate Tank Waste Retrieval Operations } \\
\hline \multicolumn{9}{|l|}{ Malntaln Tank Waste Relrfeval Syslem } \\
\hline \multicolumn{9}{|l|}{ slore recycle water } \\
\hline \multicolumn{9}{|l|}{ Revievo SST Wasto } \\
\hline Retrleve DST Waste & 10 & $T$ & & & & & & 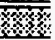 \\
\hline
\end{tabular}

D\&D Tank Waile Relrleval Syslem 
WHC-SD-WM-RPT-268, Rev. 0

FIGURE 3. IMMOBILIZED WASTES INTERIM STORAGE TIME LINE

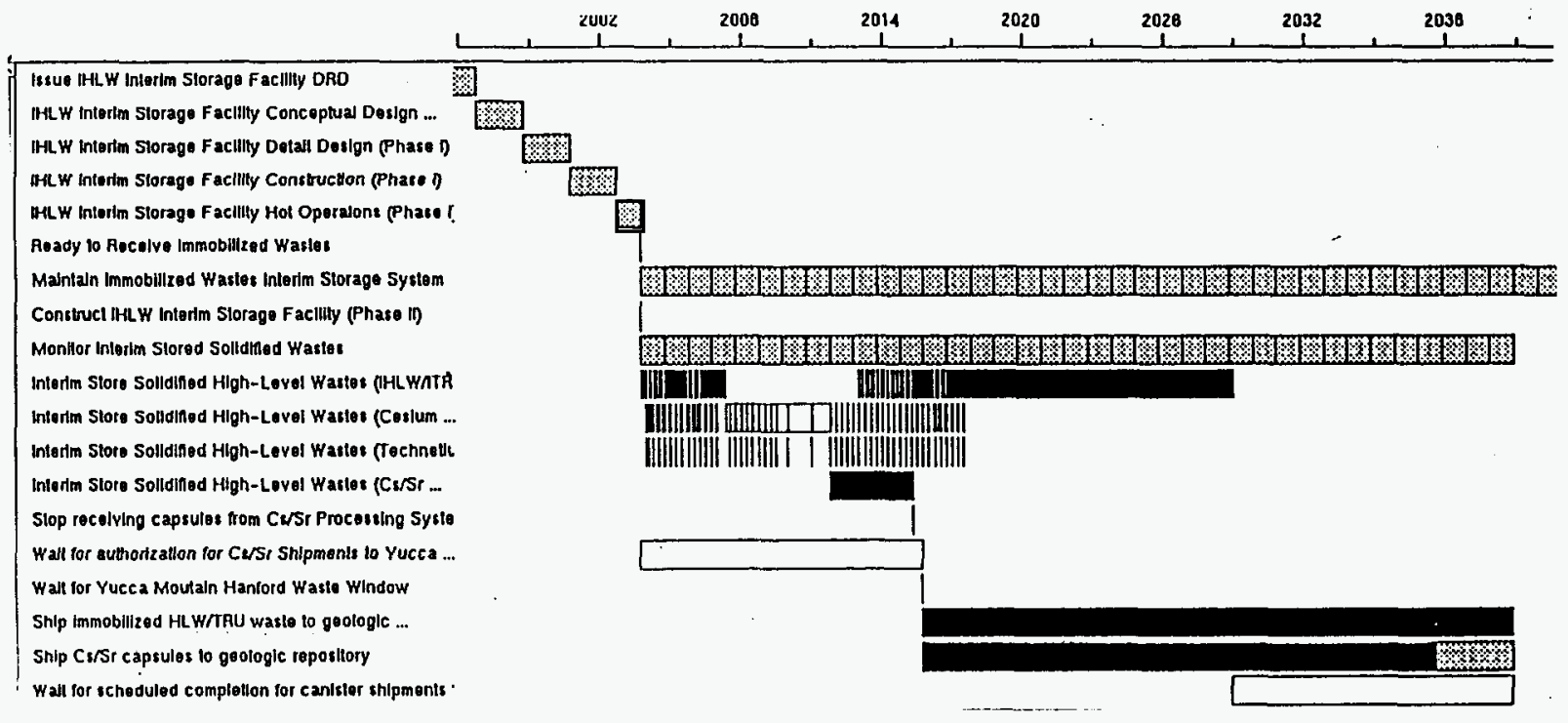


WHC-SD-WM-RPT-268, Rev. 0

FIGURE 4. TOTAL STORED TANK WASTE VERSUS TIME

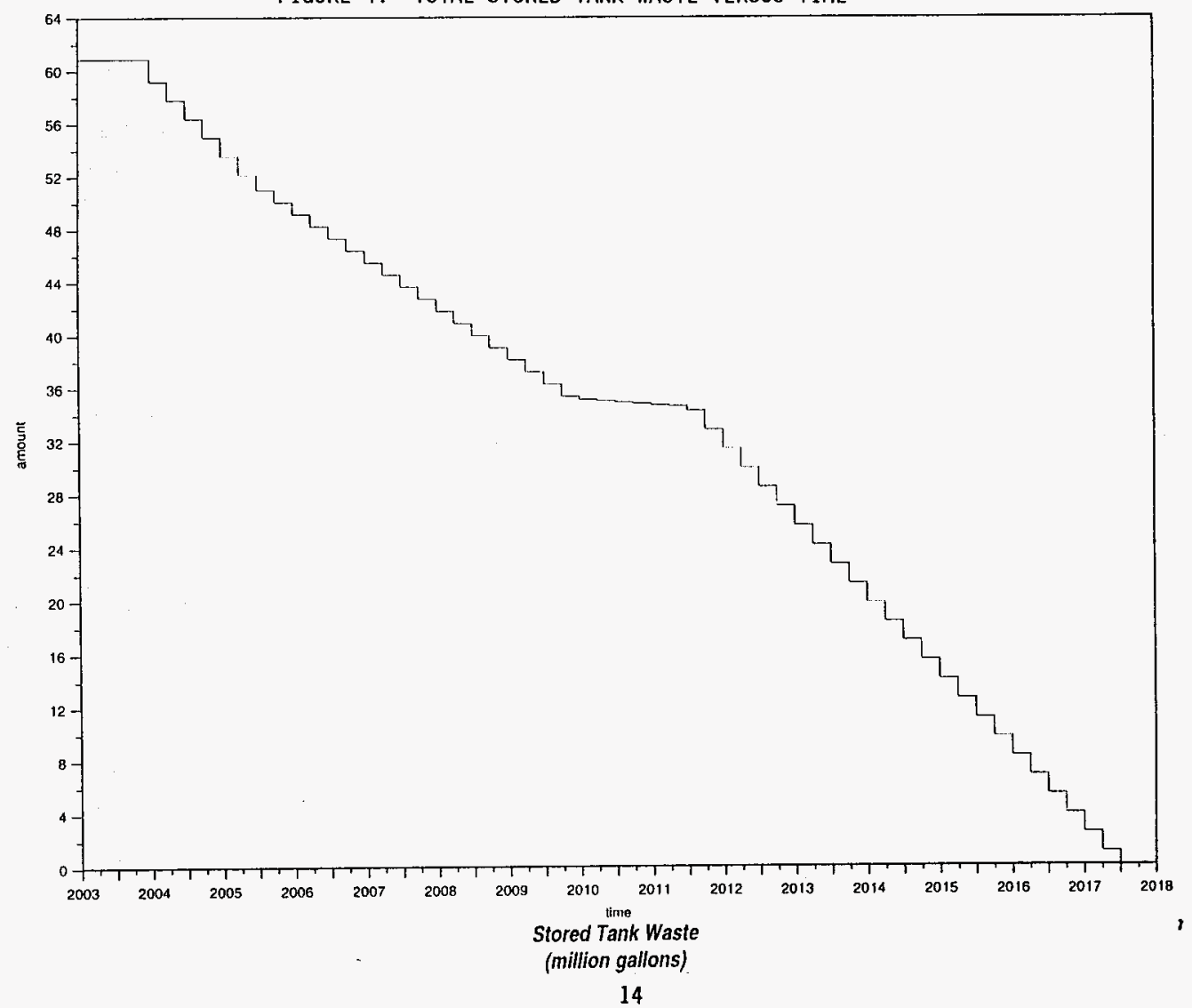




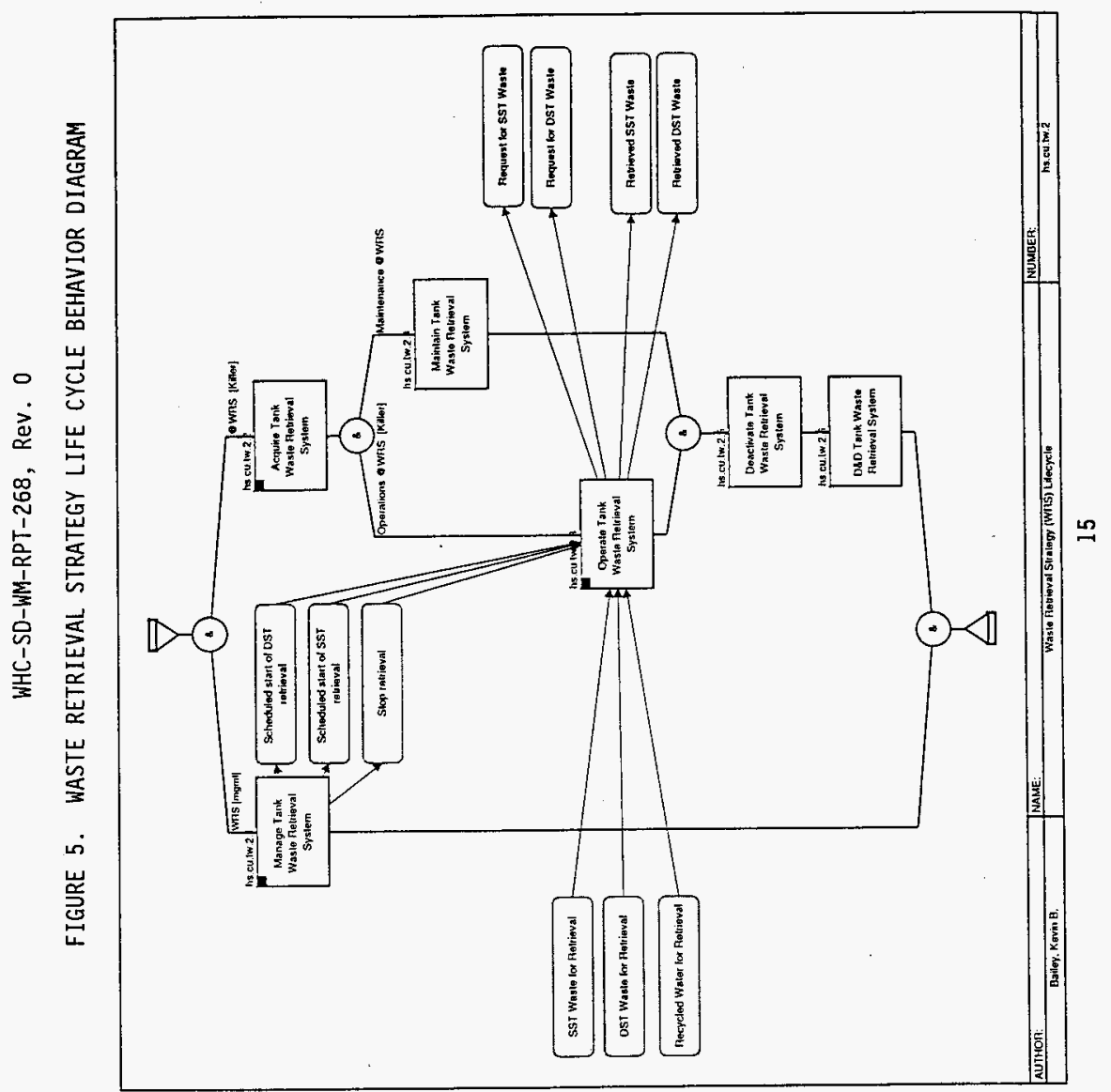


WHC-SD-WM-RPT-268, Rev. 0

FIGURE 6. SINGLE SHELL TANK RETRIEVAL (CUMULATIVE DILUTE) VERSUS TIME

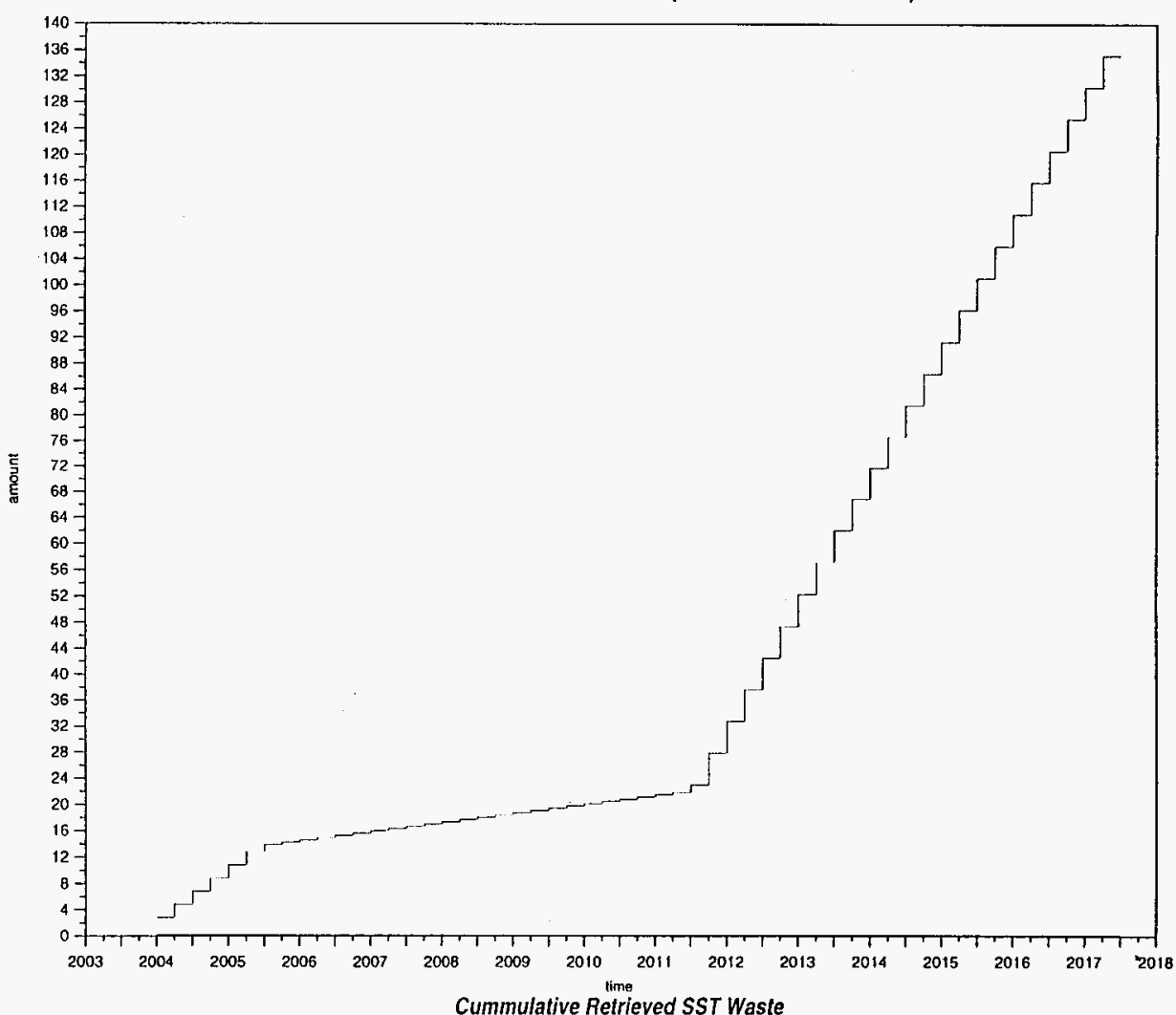

(million gallons) 


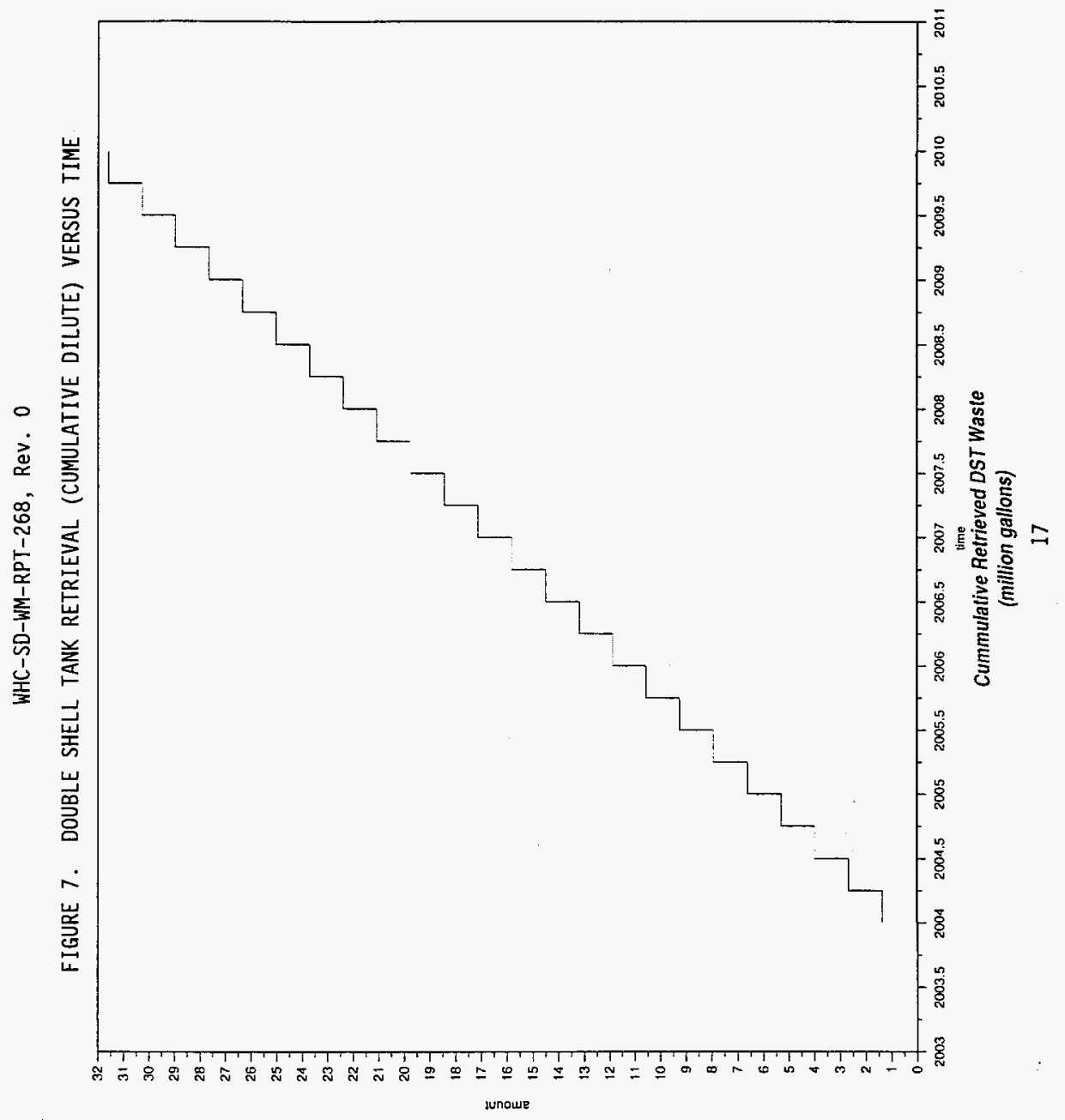


WHC-SD-WM-RPT-268, Rev, 0

FIGURE 8. PRETREATED HLW/TRU LAG STORAGE USAGE

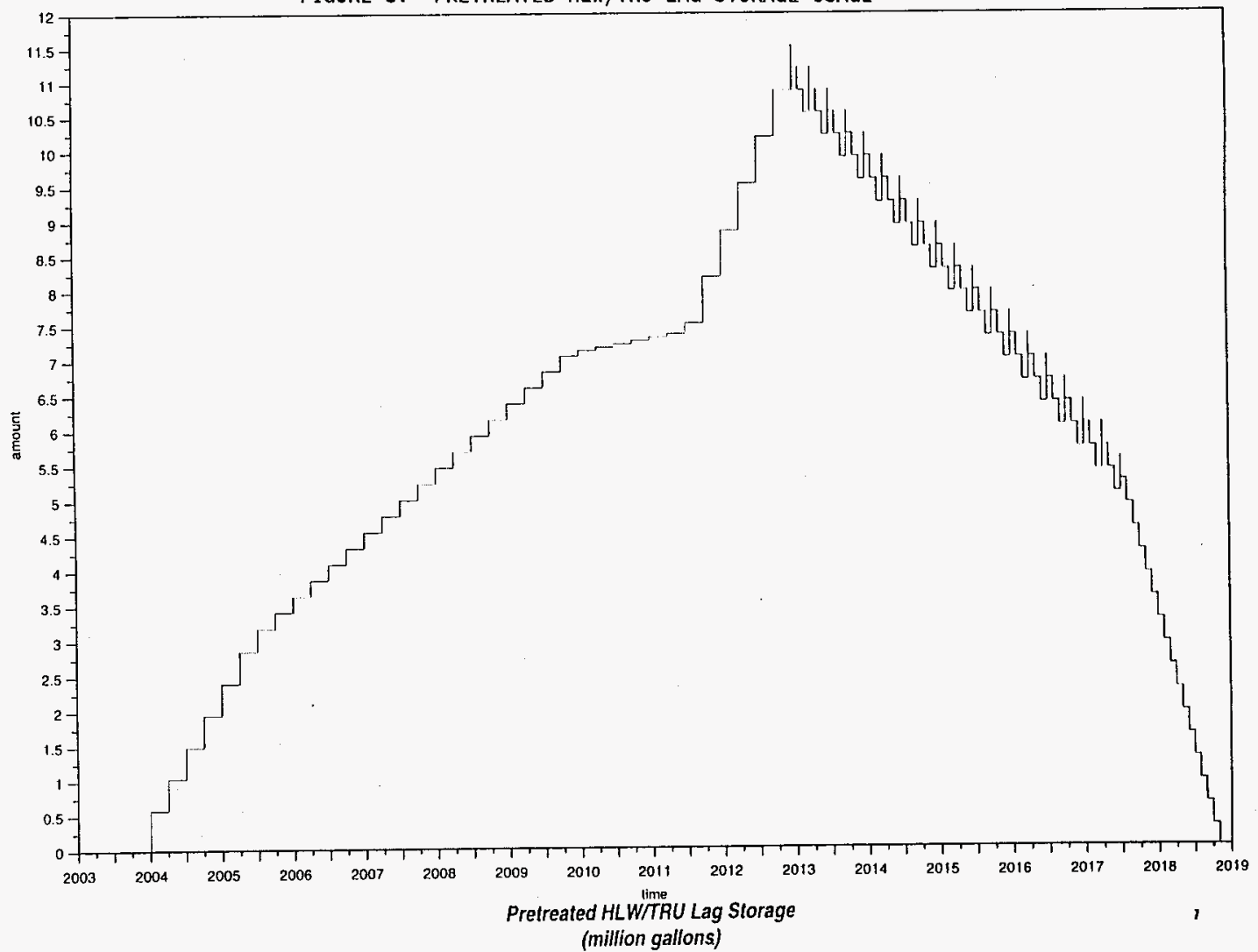




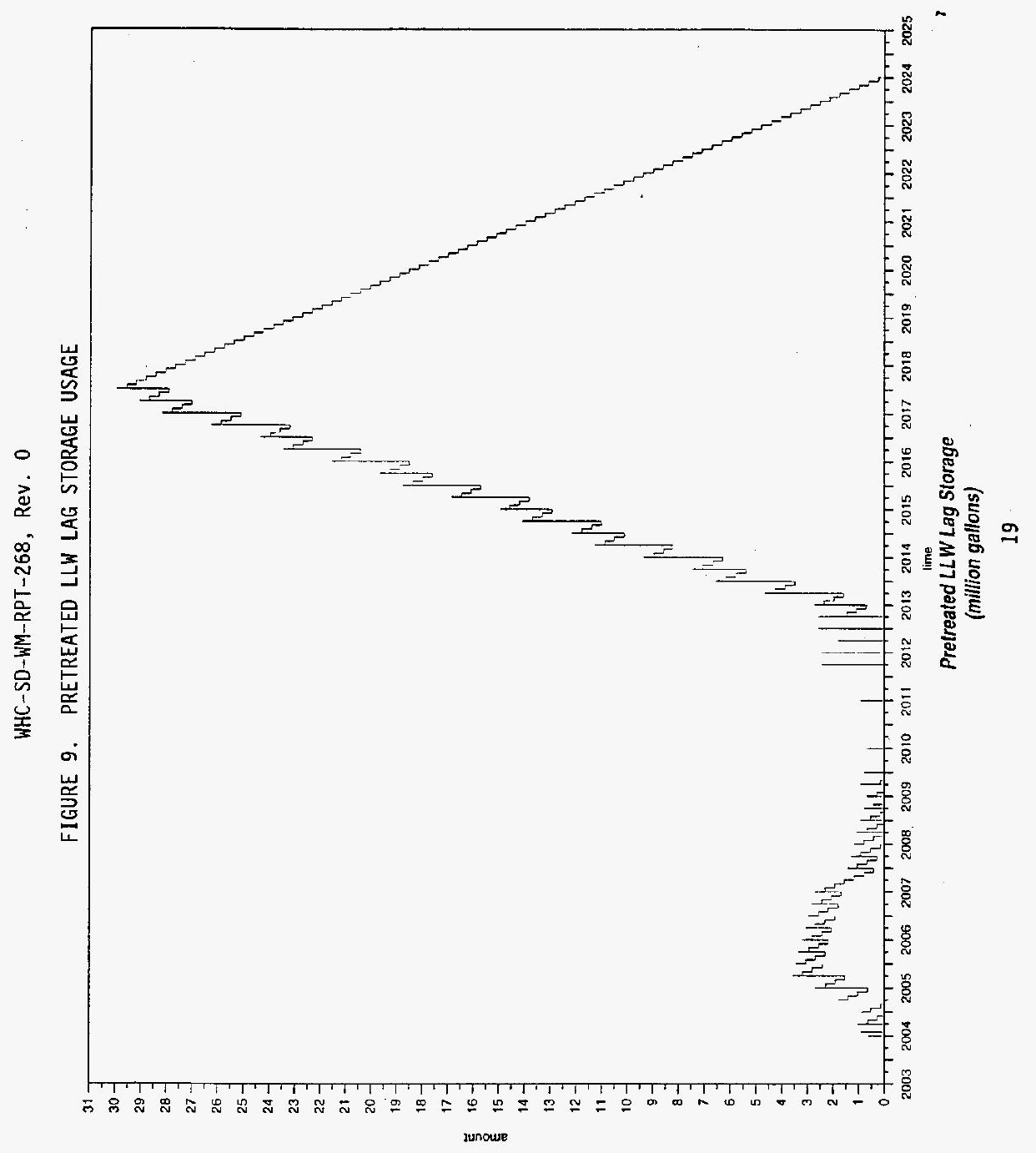


WHC-SD-WM-RPT-268, Rev. 0

FIGURE 10. INTERIM STORED HLW/TRU GLASS VERSUS TIME

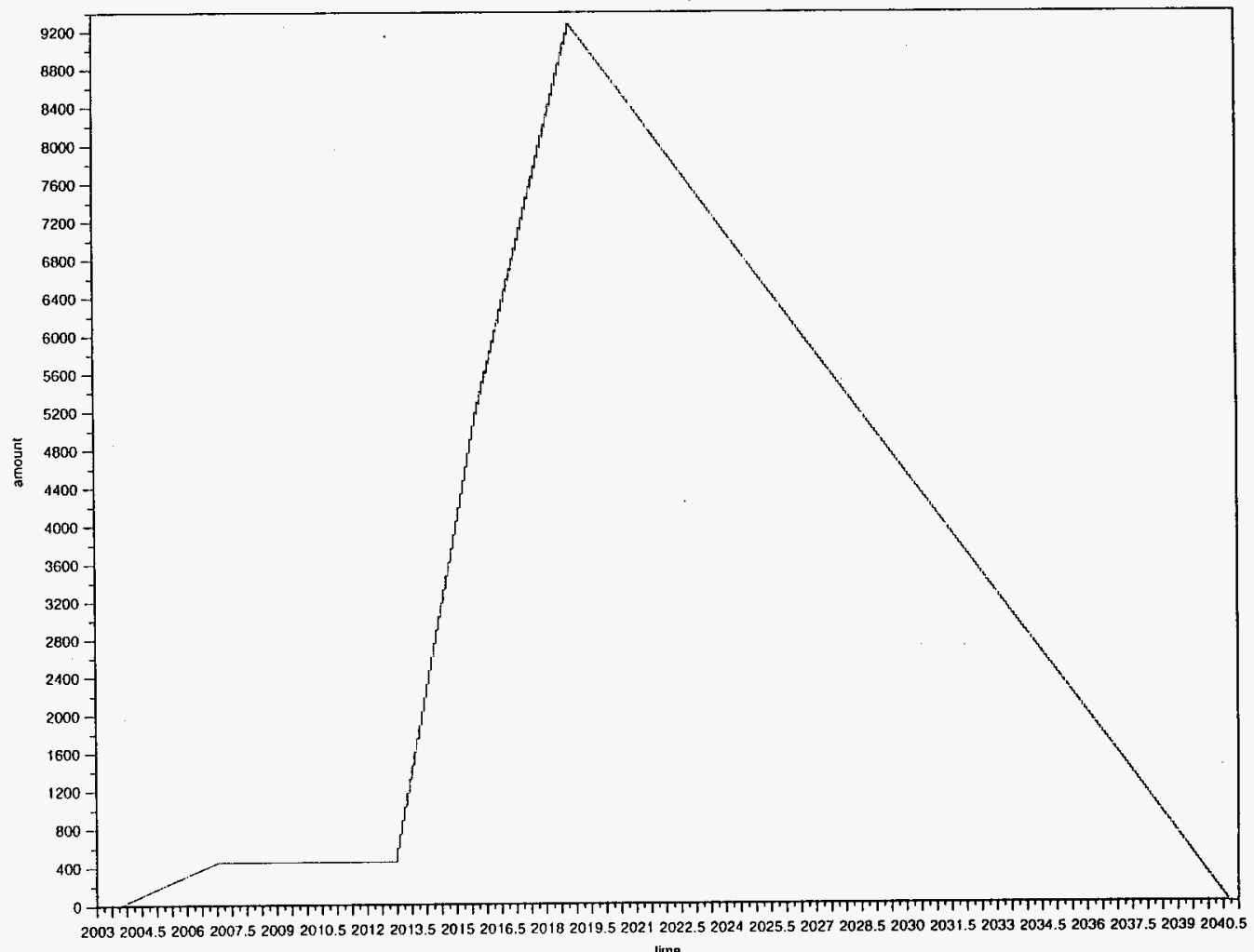

Interim Stored HLW/TRU Waste

(cubic meters) 


\section{DISTRIBUTION SHEET}

\begin{tabular}{|c|c|c|c|c|c|}
\hline \multirow{2}{*}{$\begin{array}{l}\text { To } \\
\text { Distribution }\end{array}$} & \multirow{2}{*}{\multicolumn{3}{|c|}{$\begin{array}{l}\text { From } \\
\text { SE Risk Management \& Modeling }\end{array}$}} & \multicolumn{2}{|l|}{ Page l of l } \\
\hline & & & & \multicolumn{2}{|c|}{ Date $9 / 26 / 96$} \\
\hline \multirow{2}{*}{\multicolumn{4}{|c|}{ Project Title/Work Order }} & \multicolumn{2}{|c|}{ EDT No. 618215 - } \\
\hline & & & & \multicolumn{2}{|l|}{ ECN No. } \\
\hline Name & MSIN & $\begin{array}{c}\text { Text } \\
\text { With } \\
\text { All } \\
\text { Attach. }\end{array}$ & $\begin{array}{l}\text { Text } \\
\text { Only }\end{array}$ & $\begin{array}{l}\text { Attach./ } \\
\text { Appendix } \\
\text { Only }\end{array}$ & $\begin{array}{c}\text { EDT/ECN } \\
\text { Only }\end{array}$ \\
\hline
\end{tabular}

\section{WHC}

N. G. Awadalla

K. B. Bailey

K. E. Carpenter

D. D. Frank

B. C. Gneiting

N. J. Graves

R. W. Harmsen

B. J. Knutson

A. K. Lee

S. P. Otte

L. G. Peck

D. F. Salsman

RL

D. J. Francis

Central Files (Original)

Log Book - D. D. Frank
H6-35

H6-33

H6-35

H6-35

H6-35

H6-35

H6-35

H6-35

H6-33

H6-35

H6-35

H6-35

K6-51

A3-88

H6-35 $x$

$x$
$x$
$x$
$x$
$x$
$x$
$x$
$x$
$x$
$x$
$x$
$x$
$x$

$X$
$X$ 